\title{
Editorial
}

\section{RECENT DEVELOPMENTS IN THE CHEMOTHERAPY OF LEPROSY}

The use of chaulmoogra (hydnocarpus) oil may well be regarded as the first step towards effective chemotherapy for leprosy. Although an ancient remedy, it began to attract attention in medical circles in the second half of the nineteenth century, following the first comprehensive description of its use for leprosy by Mouat, ${ }^{1}$ a surgeon in the Bengal Medical Service, in 1854. It was used fairly extensively in the first few decades of this century, but the pain caused by its administration, coupled with reports of relapse in many patients, were disconcerting and by 1941 its use had markedly diminished. In the late 1930s however, a number of chemical compounds were under development for streptococcal infections, including sulphonamides and chemically-related sulphones. Working in the National Leprosarium at Carville, Louisiana, USA, Faget first tried sulphanilamide in a group of patients, but without success. His later use of Promin (glucosulphone sodium) gave impressive results ${ }^{2}$ and this led to the use of two other compounds, Diasone (sulphoxone sodium) by Edwin Muir and sulphetrone by Frank Davey (a former editor of this journal), both of whom reported good results. It was however dapsone, a compound synthesized by Fromm and Whittmann in 1908 and used for the treatment of streptococcal mastitis in veterinary medicine, which attracted the attention of Robert Cochrane in 1945 and very soon achieved widespread use, giving rise to the hope that it would not only cure or arrest the disease in individual patients, but also lead to the control of leprosy by mass use in endemic areas.

Dapsone achieved cure or arrest of the disease in hundreds of thousands of patients and probably helped to reduce the spread of bacilli in communities where it was used, but it failed in the above objectives for two main reasons. First, health services and leprosy control programmes as we understand them today were either poorly developed or nonexistent. Second, bacillary resistance to dapsone was revealed by WHO and other agencies from the 1960s onwards to be widespread and increasing in many parts of the world. Partly to offset this situation, other compounds were added to dapsone in the 1970s, including the pioneering combination of dapsone, isoniazid, prothionamide and rifampicin by Freerksen and colleagues in an eradication programme in Malta. ${ }^{3}$ However, by the time of the XI International Leprosy Congress in Mexico in November 1978, the situation generally with regard to the chemotherapy of leprosy was almost chaotic and it was clear that radical changes were needed. Apart from the spectre of increasing dapsone resistance (coupled with fears about the longer-term significance of organisms persisting despite apparently adequate courses of treatment), the number of drugs in use and the bewildering range of combinations, was alarming. It included dapsone, acedapsone, rifampicin, clofazimine, 
prothionamide/ethionamide, isoniazid, thiacetazone, thiambutosine and long-acting sulphonamides. More than one experienced observer commented that current drug regimens were unduly complicated for field workers and patients.

In 1981, under the dynamic leadership of Dr H. Sansarricq, Chief Medical Officer, Leprosy, WHO convened a meeting of experts in Geneva with the following objectives: 1, to review the information collected since 1976 (the year when the WHO Expert Committee on Leprosy last met) on the problems related to chemotherapy and chemotherapeutic regimens of leprosy; 2, to recommend, for use in leprosy control programmes, appropriate multidrug regimens for multibacillary case, including new, treated and drug-resistant cases, whether clinically suspected or proved; 3 , to recommend regimes for paucibacillary cases; and 4, to identify further research needs in the clinical and operational aspects of chemotherapy of leprosy.

The findings were published in a WHO Report of $1982,{ }^{4}$ which has now become part of the history of the control of this disease- 'Chemotherapy of leprosy for control programmes', advising regimens of relatively short duration for all cases of leprosy, based on the use of two drugs (dapsone and rifampicin) for paucibacillary, and three drugs (dapsone, rifampicin and clofazimine) for multibacillary cases. 'MDT' had started. In the early years, largely due to fears that implementation might be difficult or even hazardous, many agencies considered that it was essential to devote much time and effort to orientation and training of staff and the provision of 'optimum' facilities in control programmes before implementation-and progress was therefore slow. However, as the years went by and more experience was gained, it became increasingly clear that the regimens were remarkably robust under a range of field conditions and that implementation could safely be achieved using general staff and referral centres, with extension to involve primary health care workers.

A series of reports and publications from WHO in the 1980's described the widening use of MDT in virtually all leprosy-endemic countries, accompanied by progressive reduction in prevalence rates and a steadily accumulating total of patients cured and released from treatment. In 1991, the World Health Assembly, obviously convinced of the momentous progress being made, adopted a resolution calling for the elimination of leprosy as a public health problem (less than 1 case per 10,000 of the population) by the year 2000. By 1993, WHO confirmed that, 'The elimination of leprosy is now under way', quoting a reduction of prevalence from 5.4 million in 1983 to 2.3 in that year. ${ }^{5}$ At the beginning of this year (1997), WHO estimated $1 \cdot 15$ million cases worldwide and recorded a reduction in recorded cases to $888,340 .^{6}$

In the September issue of the journal (page 285), there is a review of the WHO Meeting on Chemotherapy Research in Leprosy, Madras, India, January 1997, which includes reference to 'second generation MDT regimens' of significantly shorter duration than those currently advised by WHO. Dr Panniker (WHO) presented evidence from a multicentre trial that single-lesion paucibacillary leprosy could be treated with a single day's dose of three drugsrifampicin, ofloxacin and minocycline ('ROM'). The full findings of this important study, which are to appear in the Indian Journal of Leprosy in the near future, ${ }^{7}$ are reprinted on page 000 of this issue.

In May this year, the Seventh WHO Expert Committee, meeting in Geneva, endorsed these findings, together with important changes in the duration of treatment for multibacillary cases. The content and wording of these recommendations by the Committee, which appear in the latest Status Report from the Action Programme for the Elimination of Leprosy, Updated $1997,{ }^{8}$ clearly warrant careful study: 


\section{' FURTher ShORTENING DURATION OF MB LEPROSY TREATMENT}

Currently MB leprosy includes all smear-positive patients as well as patients with more than five lesions. Among the newly detected cases, the skin-smear positive patients represent only $13 \%$ of the total number of leprosy patients, and $48 \%$ of those classified as MB leprosy. Because rifampicin is by far the most powerful bactericidal drug against $M$. leprae, and more than $99.999 \%$ of viable organisms (which is the limit of detectability by current technology) are killed by the administration of three monthly doses of rifampicin, it can be assumed that the elimination of drug-susceptible organisms is almost entirely due to the bactericidal effect of the initial few doses of rifampicin. The major role of the dapsone-clofazimine component in MDT is to ensure the elimination of rifampicin-resistant mutants from the bacterial population.

However, the results from both nude mouse experiments and a clinical trial have demonstrated that the bactericidal effect of the dapsone-clofazimine component was significantly greater than expected; three months of treatment killed more than $99.999 \%$ of viable $M$. leprae, suggesting that the rifampicin-resistant mutants in an untreated lepromatous patient are likely to be eliminated by 3 to 6 months of treatment with the dapsone-clofazimine component in MDT regimen.

The Seventh WHO Expert Committee on Leprosy, which met in Geneva from 26 May to 3 June 1997, considered the possibility of further shortening the duration of MDT. This possibility is being evaluated in an ongoing rifampicin-ofloxacin field trial, which is a multicentre, double-blind trial organized by the Steering Committee on Chemotherapy of Mycobacterial Diseases (THEMYC), a component of the UNDP/World Bank/WHO Special Programme for Research and Training in Tropical Diseases (TDR). Patients were randomized into four groups and treated, respectively, with 24 months of standard WHO-MDT (as positive control), 12 months of WHO-MDT, 12 months of WHO-MDT plus ofloxacin $400 \mathrm{mg}$ daily during the initial four weeks, and rifampicin $600 \mathrm{mg}$ plus ofloxacin $400 \mathrm{mg}$ daily for four weeks. Each tested group had about $500 \mathrm{MB}$ cases. After three to five years of follow-up from intake (or two to four years of follow-up after stopping treatment with any of the three shorter tested regimens), not a single relapse has been detected so far in the trial, suggesting that all three tested regimens are as effective as that of the 24-month standard WHO-MDT regimen. In other studies, including those on defaulted cases, patients who received 12 or fewer doses of MDT performed as well as others who took complete treatment.

Based on all the above information, the Expert Committee considered it possible that the duration of the current MDT regimen for MB leprosy could be further shortened to 12 months without increasing the risk of developing rifampicin-resistance.

\section{FLEXIBLE DRUG DELIVERY}

It was also agreed that, because of poor coverage of the health services in most of the leprosyendemic countries, supervision of the monthly administered drugs by health workers may not always be possible. In that case, more than a month's supply of MDT blister packs may be provided to the patient. But every effort should be made to educate the patient to take the monthly and daily components of MDT regularly, and to identify a family or community member who can supervise the monthly drug administration. In addition, patients who selfreport for diagnosis and treatment may be considered as sufficiently motivated to take full responsibility for their own care, provided they are given appropriate information and 
guidance regarding the dosage, rhythm and necessary duration of treatment, and are advised to report any untoward signs/symptoms promptly. This will help to make MDT easily accessible even to those who live in difficult-to-access areas, to the benefit of both the patients and the health service personnel.

\section{TREATMENT OF SINGLE-LESION PB LEPROSY}

There is some evidence to suggest that single skin-lesion leprosy is a clinical entity and may be cured by a limited amount of chemotherapy, so a separate regimen for these patients will be useful. The efficacy of a single dose of drug combination consisting of rifampicin $600 \mathrm{mg}$, ofloxacin $400 \mathrm{mg}$ and minocycline $100 \mathrm{mg}$ (ROM) for the treatment of single-lesion PB leprosy has been proved in a multicentre, double-blind field trial in India. Although a single dose ROM proved marginally less effective, in terms of clinical improvement, than the sixmonth MDT, the operational advantages of a single dose treatment over the six-month treatment are enormous, especially when it is taken into account that, in some countries such as India, more than $50 \%$ of newly detected cases belong to this category. The Committee therefore considered that a single dose ROM is an acceptable and cost-effective alternative regimen for the treatment of single skin-lesion PB leprosy."

A further development of potentially great importance is the acceptance (July 1997) by the Government of India (Leprosy Division, Directorate General of Health Services) of the above recommendations for both multibacillary and single-lesion paucibacillary leprosy. The 'Government of India Guidelines on Modified $M D T$ '9 have already been drawn up for distribution; the necessary 'ROM' drugs will be in place by October this year and it is hoped to start the new programme in November. If only in consideration of the fact that India still accounts for $62 \%$ of all global cases and also has a high percentage of all newly-detected cases yearly, the impact of these changes may indeed prove to be enormous.

For many years - in fact for centuries-leprosy has been regarded as a slow-moving disease with limited resources for the treatment of those afflicted. That this has changed profoundly and almost beyond recognition must surely now be apparent to all concerned. It is of course true that programme performance has improved in many parts of the world; political commitment is now seen where it did not exist before; drugs are available, free of charge and in blister-calendar packs to all patients who need them and in many leprosy-endemic countries general health services, including BCG immunization, have improved considerably in recent years. Nevertheless, the main element in the success of leprosy control in recent decades undoubtedly centres on the use of multiple drug therapy, leading to the increasingly strong expectation of achieving elimination levels by the year 2000. We should congratulate those who, in 1981, had the vision to convene a meeting in Geneva and the experts who used their knowledge and experience to formulate regimens of such historic importance. However, this is not a time for complacency. Dr S. K. Noordeen, Director of the Action Programme for the Elimination of Leprosy, has recently stressed the need to reach the remaining 2 million patients by: 1, making MDT available to all health facilities in endemic countries; 2, using Leprosy Elimination Campaigns (LEC) and Special Action Projects for the Elimination of Leprosy (SAPEL); 3, encouraging high political commitment; and 4, generating community participation, involvement and action through mass communication and a 'trialogue' approach involving patients, people and providers. ${ }^{10}$ If we combine these approaches with the careful implementation of the recent changes recommended by the Expert Committee, we 
surely have an opportunity, absolutely beyond parallel in the history of this disease, to achieve elimination levels by the year 2000 .

Honorary Consultant:

Department of Dermatology,

A. COLIN McDOUGALL

The Churchill Hospital, Headington,

Oxford OX3 7LJ, United Kingdom

Address for correspondence: 87 Lower Radley,

Near Abingdon, Oxfordshire OX14 3BA, United Kingdom

\section{References}

1 Mouat FJ. Notes on native remedies No 1: the chaulmoogra. Ind Ann Med Sci, 1854; 1: 646-652.

2 Faget GH, Pogge RC, Johansen FA, Dinan JF, Prejean BM, Eccles CG. The promin treatment of leprosy, A progress report. US Public Health Reports, Number 48. 1943. United States Government Printing Office, Washington.

${ }^{3}$ Freerksen E, Rosenfeld M. Leprosy eradication project of Malta. Chemotherapy, 1997; 23: 356-386.

${ }^{4}$ WHO. Chemotherapy of leprosy for control programmes. Report of a WHO Study Group. Technical Report Series 675. World Health Organization, Geneva, 1982.

5 WHO. Leprosy elimination: meeting the challenge. WHO/CTD/LEP/93.2. World Health Organization, Geneva, 1993.

6 WHO, Report of the third meeting of the leprosy elimination advisory group, Geneva, 16th and 17th July, 1997. WHO/LEP/97.6. World Health Organization, Geneva, 1997.

7 WHO. Action Programme for the Elimination of Leprosy. Efficacy of single dose multidrug therapy for the treatment of single-lesion paucibacillary leprosy. Ind J Lepr, 1997; 69(2): 121-129.

8 WHO. Action Programme for the Elimination of Leprosy. Status Report. Updated 1997. WHO/LEP/97.4. World Health Organization, Geneva, 1997.

${ }^{9}$ Government of India. Leprosy Division, Directorate General of Health Services. Government of India Guidelines on Modified MDT. DGHS, Ministry of Health and Family Welfare, Nirman Bhavan, New Delhi 110011, India, 1997.

10 WHO. Report of an informal consultation on community action for the elimination of leprosy, Dhaka, Bangladesh, 5-6 March 1997. WHO/LEP/97.5. In press. World Health Organization, Geneva, 1997. 